\title{
A Olimpíada de Programação de Computadores para Estudantes do Ensino Fundamental: A interdisciplinaridade por meio do software Scratch
}

\section{Neuza Terezinha Oro ${ }^{1}$, Ariane Mileidi Pazinato ${ }^{2}$, Adriano Canabarro Teixeira ${ }^{1}$, Adler Jonas Gross ${ }^{3}$}

\author{
1Instituto de Ciências Exatas e Geociências - Universidade de Passo Fundo (UPF) \\ BR 285, São José, 95.052-900, Passo Fundo, RS - Brasil \\ ${ }^{2}$ Faculdade Meridional - Imed Passo Fundo \\ Passo Fundo, RS - Brasil \\ ${ }^{3}$ Instituto Federal de Educação, Ciência e Tecnologia Sul Rio Grandense (IFSul) \\ Passo Fundo, RS - Brasil \\ neuza@upf.br, ariane.pazinato@imed.edu.br, teixeira@upf.br, \\ adlerjonasgross@gmail.com
}

\begin{abstract}
The use of technological resources, especially of computers in education, comes qualifying teaching and learning processes. This perception gains strength when analyzing an existing partnership between the University of Passo Fundo and the City Department of Education of Passo Fundo, Brazil, which has been consolidated by carrying out projects in the educational area of information technology and digital inclusion. One of this projects is the Computer Programming Olympiad for Elementary School Students, using Scratch. This article reports the methodology of the Olympics, and presents the analysis of two constituents challenges of the final test. Two editions were held in 2013 and 2014, attended by 29 teams from the city of Passo Fundo and region. In them it was possible to, among other things, establish that programming computers have great fascination on young people and has great didactic and pedagogical potential, developing skills such as logical reasoning, procedural thinking and interdisciplinary.
\end{abstract}

Keywords: computer programming, Olympics, Scratch, digital inclusion, mathematical, logical reasoning.

Resumo. $O$ uso de recursos tecnológicos, em especial de computadores na educação, vem qualificando processos de ensino e aprendizagem. Esta percepção ganha força ao analisar uma parceria existente entre a Universidade de Passo Fundo e a Secretaria Municipal de Educação de Passo Fundo, Brasil, que tem se consolidado através da realização de projetos na área de informática educativa e inclusão digital. Um desses projetos é a Olimpíada de Programação de Computadores para Estudantes do Ensino Fundamental, usando o Scratch. Este artigo relata a metodologia da Olimpíada, bem como apresenta a análise de dois desafios constituintes da prova final. Foram realizadas duas edições, em 2013 e 2014, das quais 
participaram 29 equipes da cidade de Passo Fundo e região. Nelas foi possível constatar, entre outros elementos, que a programação de computadores apresenta grande fascínio nos jovens e possui grande potencial didático-pedagógico, desenvolvendo habilidades como o raciocínio lógico, pensamento procedimental e interdisciplinar.

Palavras-chave: programação de computadores, olimpíadas, Scratch, inclusão digital, conceitos matemáticos, raciocínio lógico.

\section{Introdução}

É indiscutível a importância que a área de Tecnologia da Informação (TI) tem assumido no mundo contemporâneo, instituindo-se como elemento determinante no desenvolvimento de pessoas, empresas, municípios, estados e países. Motor do desenvolvimento econômico e vetor de agregação social, as tecnologias digitais transformam profundamente o mundo e abrem inúmeras perspectivas de ampliação da qualidade de vida dos indivíduos, de transparência para as instituições públicas e de transformação da sociedade como um todo. Entretanto é possível identificar claramente dois paradoxos: apesar da importância fundamental da área e de seu crescimento, existe um déficit de profissionais especializados neste setor, embora presente nas instituições de ensino há mais de 20 anos, não tem implicado melhorias nos resultados da educação ao redor do mundo.

De acordo com dados divulgados pela IDC América Latina, existe atualmente, no Brasil, uma carência de cerca de 39,9 mil profissionais de tecnologia sendo que até 2015, esse número deve crescer para 117 mil vagas abertas sem que os empregadores encontrem profissionais qualificados para atendê-las. Tal demanda já é reconhecida como urgente pela comunidade internacional e criando-se projetos como o code.org, liderado por grandes nomes da política, cultura, entretenimento e negócios do século XXI. No Brasil, diz o estudo, somente em áreas como rede essencial, segurança, telefonia IP e redes sem fio haverá uma lacuna de 23,6 mil profissionais. Percentualmente, segmentos como comunicações unificadas, vídeo, computação em nuvem, mobilidade, data center e virtualização serão as áreas com maior número de vagas abertas em comparação com o volume de profissionais qualificados disponíveis.

Neste contexto Passo Fundo, Rio Grande do Sul, Brasil ocupa lugar de destaque e estratégico no cenário da TI fora das capitais nacionais uma vez que conta com uma grande base de empresas na área, associações de profissionais e empresas da área de Tecnologia da Informação (TI), incubadoras empresariais e parques científicos e tecnológicos, além de vários cursos de nível médio e superior de graduação e pósgraduação na área de TI.

Diante desta realidade, é fundamental que se oportunizem espaços para o desenvolvimento de competências na área de TI desde o ensino fundamental, pois além de auxiliar a sanar esta demanda do mercado profissional, as tecnologias da informação podem ser um excelente aporte para os processos de ensinar e de aprender nas diferentes áreas do conhecimento.

Nesta perspectiva, o Grupo de Estudo e Pesquisa de Inclusão Digital, da Universidade de Passo Fundo (UPF), em parceria com a Secretaria Municipal de 
Educação de Passo Fundo, vem promovendo há dois anos a Olimpíada de Programação para Estudantes do Ensino Fundamental. A Olimpíada é destinada a estudantes do $6^{\circ}$ ao $9^{\circ}$ ano de escola públicas e tem por objetivos promover a introdução de programação de computadores no ensino fundamental, através do software Scratch; criar novas formas de utilização dos recursos de informática das escolas para o auxílio nas diversas áreas do conhecimento; despertar interesse para as áreas de matemática e informática; proporcionar novos desafios aos estudantes, visando à interdisciplinaridade; aproximar a Universidade das redes públicas de ensino.

O presente artigo tem por objetivo relatar a experiência das duas edições da Olimpíada, que ocorreram, respectivamente, em 2013 e 2014 e analisar dois dos desafios da prova final que envolveram conceitos matemáticos.

\section{Fundamentação Teórica}

As tecnologias contemporâneas contribuem ativamente para a transformação do mundo, auxiliando na melhoria da qualidade de vida dos indivíduos, no processo de transparência das ações de instituições públicas e na vida da sociedade como um todo. Por permitir a interatividade, o uso das tecnologias digitais pode ser um recurso potencializador para o processo de ensino e aprendizagem, já que a construção do conhecimento é um processo dinâmico e participativo. Havendo cooperação entre os estudantes e entre estudantes e professores, o aprendizado tende a acontecer de forma efetiva e significativa.

No contexto de constante e emergente atualização em que o mundo se encontra, muitas vezes a escola necessita da mudança de parâmetros. Para Lévy (1999) o papel da informática não é o da inteligência artificial, mas sim auxiliar na inteligência coletiva. Segundo o autor, inteligência coletiva é "“[...] a valorização, a utilização otimizada e a criação de sinergia entre as competências, as imaginações e as energias intelectuais, qualquer que seja sua diversidade qualitativa e onde quer que esta se situe."

Nesta perspectiva, o ensino de programação de computadores representa uma alternativa poderosa na qualificação da formação básica de crianças, contribuindo, potencialmente, para o processo de ensino e aprendizagem em todas as áreas do conhecimento, uma vez que possibilita o desenvolvimento do raciocínio lógico.

Para Papert (1986) programar implica capacidade para comunicar-se com o computador, utilizando uma linguagem que possa ser entendida tanto pela máquina, quanto pelo homem. Como crianças são ótimas na aprendizagem de línguas, elas facilmente aprenderiam a comunicar-se com um computador através de uma linguagem de programação.

Existem diferentes interfaces disponíveis com vistas a suportar a programação de computadores. Dentre estas linguagens que auxiliam na programação de computadores, pode-se destacar o software Scratch. Criado no Massachusetts Institute of Technology (MIT), é um recurso interdisciplinar voltado ao usuário infantil e jovem. Os comandos, no Scratch, encontram-se na forma de componentes gráficos, através de uma interface visual intuitiva, conforme mostrado na figura 1, tem se consolidado como um poderoso recurso para o aprendizado de conceitos lógicos, matemáticos e computacionais por alunos de diferentes níveis. 
CBIE-LACLO 2015

Anais do XXI Workshop de Informática na Escola (WIE 2015)

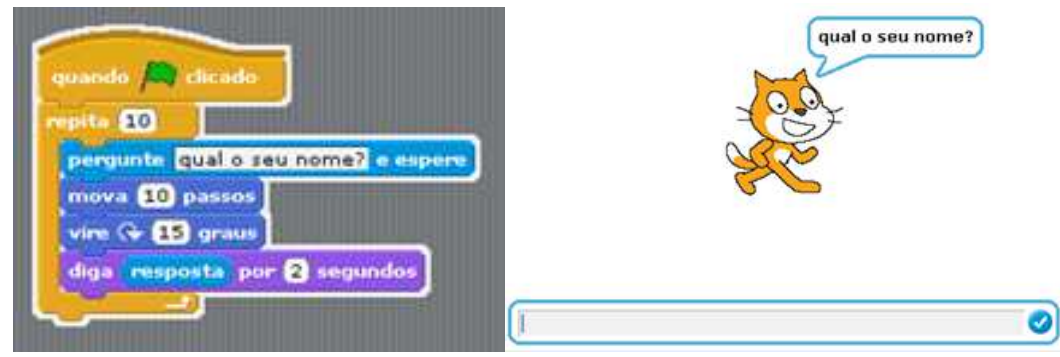

Figura 1. Tela inicial do Scratch 1.4

A programação no Scratch é feita através de blocos de comandos que são encaixados uns nos outros, formando a sequência de comandos que se deseja. Os blocos são concebidos para se encaixar apenas de uma única forma, o que faz sentido sintaticamente, evitando erros de sintaxe, porém não lógicos.

Segundo Pinto (2010), o Scratch tem muitas potencialidades, entre elas podem ser citadas as seguintes: liberdade de criação; criatividade associada a programas abertos e sem limitações do software; comunicação, colaboração e compartilhamento associados à aprendizagem e facilitados pelas ferramentas da Web que permitem a publicação direta; aprendizagem de conceitos escolares, partindo de projetos livres ou não escolarizados; manipulação de mídias, permitindo a construção de programas que controlam e misturam gráficos, animação, texto, música e som.

Além disso, possibilita aos usuários o desenvolvimento de competência para a resolução de problemas e para a concepção de projetos com raciocínio lógico, decomposição de problemas complexos em partes mais simples, identificação e eliminação de erros, desenvolvimento de ideias, desde a concepção até a concretização do projeto, concentração e perseverança (Marques, 2009).

Neste sentido, analisando a evolução do processo de aprendizagem será mais fácil observar e desenvolver formas de ensinar o que possam vir a atender as demandas atuais. Assim, nas palavras de Pozzo, "não se trata de adaptar nossas formas de aprender e ensinar a esta sociedade que mais nos exige do que nos pede, como também modificar essas exigências em função de nossas próprias crenças.” (2002).

É preciso envolver o aluno em atividades participativas, que estimulem seu raciocínio, em consonância com uma prática formativa e não meramente armazenadora de informações. Uma das possibilidades para esse envolvimento é oportunizar espaços para desenvolver a habilidade de escrever programas de computador. Quando as pessoas aprendem a programar, elas aprendem estratégias importantes para a resolução de problemas, promover a introdução de programação de computadores no ensino fundamental, através do software Scratch; criar novas formas de utilização dos recursos de informática das escolas para o auxílio nas diversas áreas do conhecimento; despertar interesse para as áreas de matemática e informática; proporcionar novos desafios aos estudantes, visando à interdisciplinaridade; aproximar a Universidade das redes públicas de ensino de design e comunicação de ideias.

Nesta perspectiva, várias propostas de inovação tecnológica no processo de ensino e aprendizagem estão sendo implementadas, dentre estas podemos citar o artigo de Gewerc e Alonso Ferreiro (2014) e Bayón, Moralles e Llorente (2014). Eles apresentam a perspectiva do aluno sobre a investigação avaliativa do projeto 
Universidad em la Sociedad Del Conocimiento. Fortalecimiento institucional de áreas dedicadas a la enseñanza universitaria con Nuevas Tecnologías (FEUNT) financiado pela Agencia Espanhola de Cooperação Internacional para o Desenvolvimento (AECID), executado pela Faculdade de Filosofía Humanidades $(\mathrm{FFyH})$ da Universidade Nacional de Córdoba (UNC), Argentina, e coordenado pela UniversidadE de Santiago de Compostela (USC), Espanha, com o objetivo geral de fortalecer a FFyH no desenvolvimento de programas destinados a melhorar as práticas de ensino através da inclusão efetiva das tecnologias. O projeto, segundo relato, é uma combinação de estratégias top-down, bottom-up e middle-out proposta por Cummings et al. (2005), articuladas em cinco programas: programa de formação de graduação e pós-graduação; programa de produção de materiais educativos; programa de investigação e desenvolvimento; programa de melhoria tecnológica; e programa de difusão, comunicação e promoção de políticas de conhecimento aberto. Para avaliar o impacto e a influência das práticas do projeto nos estudantes foram realizados questionários e um photovoice. Os resultados obtidos evidenciam trocas dos tempos e espaços dos ambientes para ensino e aprendizagem, segundo os autores a adoção de tecnologia invertida na biblioteca da instituição e nos materiais elaborados para plataforma de gestão de conteúdos são aspectos mais pontuados na avaliação. Ressaltam também o escasso trabalho colaborativo na inter-relação das plataformas virtuais com as classes presenciais. Além disso as inovações tecnológicas implementadas tem contribuído para a melhoria do ensino.

Neste sentido, em 2013, através de um trabalho interdisciplinar entre os cursos de Ciência da Computação e Matemática da Universidade de Passo Fundo foram idealizadas as Olimpíadas de Programação de Computadores de escolas públicas com o objetivo de promover a introdução de programação de computadores no ensino fundamental, através do software Scratch. Além dos desafios desenvolvidos a partir da interseção das áreas, foi criada metodologia específica para esta atividade, descrita a seguir.

\section{Metodologia das Olimpíadas}

A Olimpíada de Programação de Computadores para Estudantes do Ensino Fundamental é uma competição destinada aos estudantes de escolas da educação básica, a partir do sexto ano, de Passo Fundo e região. Ela está dividida nas seguintes etapas: inscrição, treinamento e competição.

Inscrição. Cada escola pode inscrever no máximo duas equipes, compostas por um professor responsável, um professor suplente, três alunos titulares e dois alunos suplentes do ensino fundamental, a partir do sexto ano. Para as inscrições é destinado um período de aproximadamente um mês conforme informações no site oficial da olimpíada (http://olimpiada.mutirao.upf.br/).

Treinamento. Esta etapa consiste em: oficina preparatória, desafios semanais e visitas às escolas inscritas. As equipes inscritas participaram da oficina preparatória no Laboratório Central de Informática da Universidade de Passo Fundo, onde é apresentado o regulamento, o software Scratch versão Linux e criada uma conta de usuário para cada equipe no site oficial do Scratch. São realizadas as atividades propostas pela equipe organizadora, possibilitando aos estudantes e professores, o manuseio do Scratch. 
Após a oficina, durante dez semanas, são disponibilizados desafios semanais às equipes participantes através do site oficial da olimpíada. As soluções devem ser postadas na página oficial do Scratch, por meio da conta de usuário de cada equipe. Com intuito de exemplificar as tarefas desta etapa, escolhemos a tarefa 21 de 2013: Insira um objeto que percorra um trajeto em diagonal delimitado, desde o ponto de partida até o ponto de chegada, utilizando as setas do teclado (seta direita ou esquerda). Insira, no meio deste trajeto, um obstáculo. Para superá-lo e seguir adiante o objeto deverá solicitar seu nome. Quando alcançar o ponto de chegada deve retornar ao início.

Esta tarefa requer leitura, interpretação, raciocínio lógico e aplicação dos seguintes conceitos matemáticos: direção, diagonal, coordenada cartesiana e ângulos.

A Figura 2 ilustram a solução da tarefa realizada pela equipe Avast, da Escola Estadual de Ensino Médio Armindo Edwino Schwengber, do município de Colorado e da equipe Machado, da Escola Estadual de Ensino Fundamental Dr. João Carlos Machado, de Sarandi.

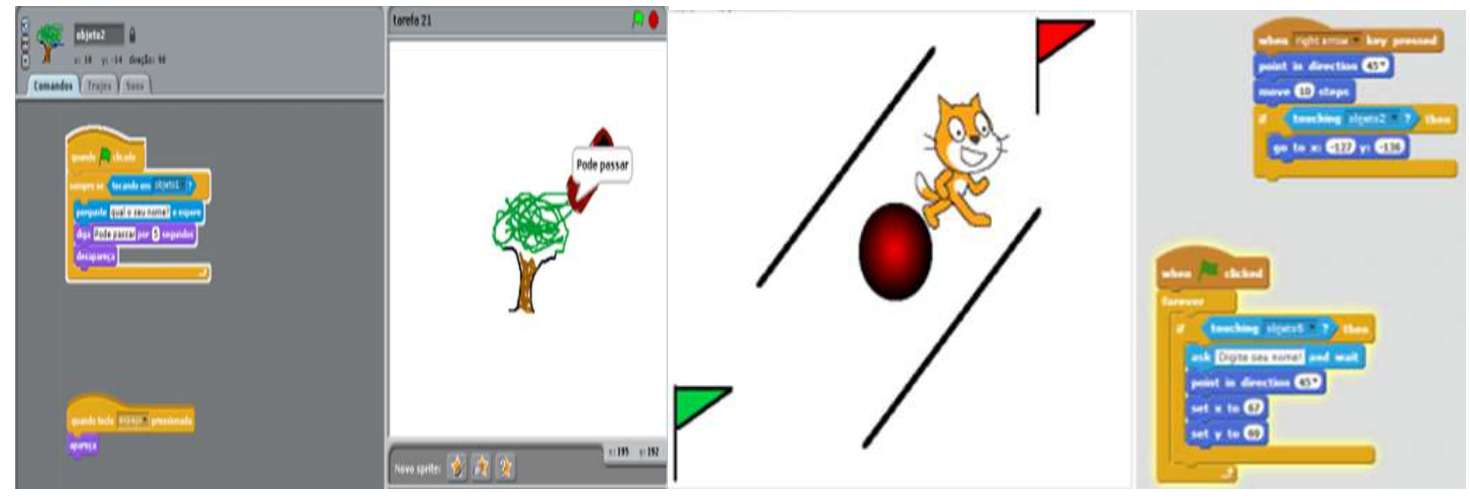

Figura 2. Liberação do caminho: Equipe Avast e Equipe Machado.

As duas equipes realizaram o proposto na tarefa. Percebemos que a Equipe Avast executou somente o que estava sendo solicitado. Já a Equipe Machado, além de realizar a programação dos objetos, criou um cenário de acordo com o contexto descrito. Comparando as soluções executadas pelas equipes, podemos afirmar que o Scratch possibilita o desenvolvimento do raciocínio lógico necessário à programação. É um ambiente adequado para expressão da criatividade na criação de cenários e objetos, interação entre sprite (objeto a ser programado), interação entre objeto e usuário, entre outros.

Competição.As equipes são recepcionadas num espaço preparado para a competição nas dependências da Universidade de Passo Fundo. Na abertura, as equipes conhecem o regulamento e as regras gerais da competição. Durante um tempo previamente determinado, as equipes recebem o material impresso contendo os desafios a serem executados, conhecem a pontuação atribuída a cada desafio e realizam a programação. Quando julgarem concluído determinado desafio, as equipes encaminham para a avaliação da banca. Ao término do tempo estabelecido, é divulgada a classificação das equipes e os vencedores. A premiação prevê primeiro, segundo e terceiro lugares.

$\mathrm{Na}$ primeira olimpíada, o foco dos desafios foi o raciocínio lógico e a matemática. Dos oito desafios propostos, três deles foram adaptados da Olimpíada 
Brasileira de Matemática para Escolas Públicas (OBMEP). Na segunda, optou-se por uma abordagem interdisciplinar. Logo, os desafios envolveram animação de histórias, sequências musicais, games e operações matemáticas. Neste artigo, escolhemos o Desafio 1 das Olimpíadas de 2013 e 2014.

Desafio 1 (2013): O macaco Kako deve subir uma escada com 18 degraus e alcançar o cacho de bananas, que está no topo desta. Só que a escada está muito lisa e Kako têm dificuldade de subir. A cada passo, Kako sobe três degraus e desliza dois.

1-Construir o objeto escada, conforme descrição.

2-Mostrar Kako subindo a escada, conforme o critério descrito.

3-Mostrar o total de passos que Kako levou para chegar ao topo da escada.

Desafio 2 (2014): Música - A casa (Vinicius de Moraes): A letra e a cifra da música encontram-se na prova disponível em http://www.youblisher.com/p/921986-2a-Olimpiada-de-Programacao-deComputadores-para-Estudantes-do-Ensino-Fundamental/

1- Crie, pelo menos, uma lista e armazene sequência de notas.

2- Programar a música conforme as notas e batidas, seguindo o ritmo e utilizando a(s) lista(s) criada(s) no item a).

3- Inserir um cenário e um objeto.

4- Fazer com que o palco e o objeto interajam, acompanhando o ritmo.

\section{Análise dos Desafios}

No desafio de 2013, é importante salientar que conceitos matemáticos, tais como simetria, deslocamento no plano cartesiano e variável, eram necessários para a construção de degraus da escada com o mesmo espaçamento, movimentação do macaco e controle de seus passos. Foram escolhidas para apresentar neste artigo as programações realizadas pelas equipes Avast e Giocondocanali, da Escola Municipal de Ensino Fundamental Giocondo Canali, do município de Tapejara, respectivamente, segundo e primeiro lugares da competição.

A Equipe Avast, em sua estratégia, na construção da escada determinou o número de passos necessários para realizar o movimento de subir três degraus e deslizar dois, para então contabilizar, na variável "passos", o total de passos que o macaco se deslocou (figura 3).

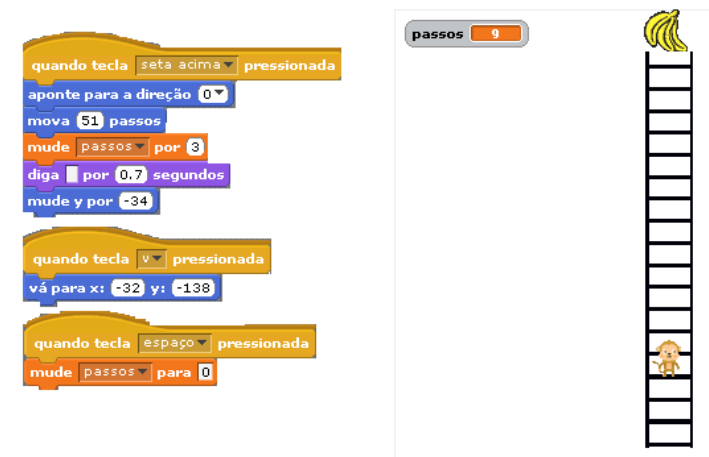

Figura 3. Inicialização da variável "passos". Posição inicial do movimento do Sprite macaco. 
A equipe inicializou corretamente a variável "passos", conforme mostrado na figura 3, e também inseriu na programação do Sprite macaco as coordenadas iniciais do movimento, bem como o controle de que reiniciasse, nesta posição, sempre que quisesse recomeçar o movimento.

No desenvolvimento, a equipe não realizou a programação para controlar a chegada ao topo da escada, não cumprindo na totalidade o desafio.

A equipe Giocondocanali optou pela estratégia de descrever as coordenadas do movimento do macaco, ou seja, a posição dos degraus, computando na variável "passos" o total de passos realizados até chegar à posição definida pela equipe (ver figura 4). Nos blocos de comando, também são apresentados a inicialização da variável e do movimento do macaco.
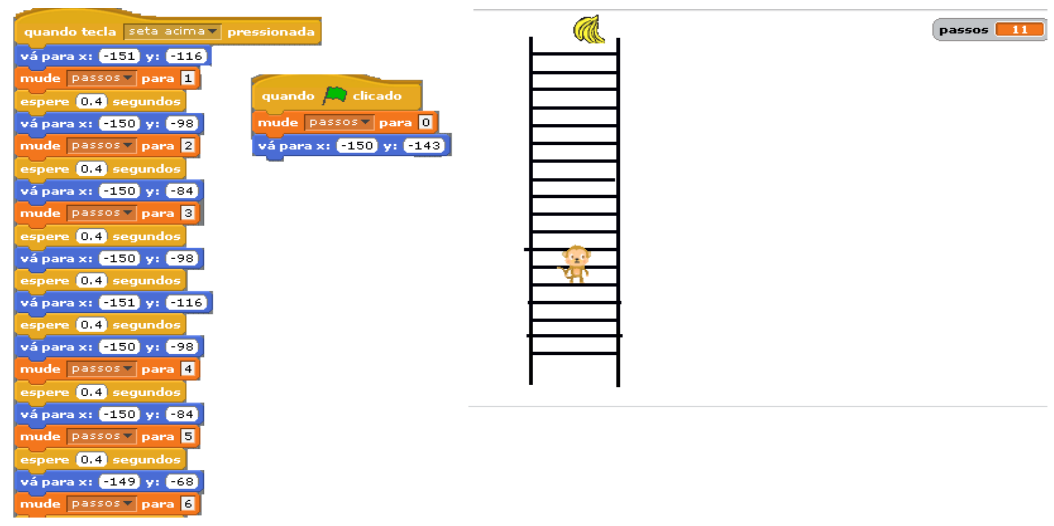

Figura 4. Programação do deslocamento e palco de execução da programação

Analisando a programação realizada pelas equipes, ressalta-se que ao expor as estratégias ou formas de resolver o desafio, as mesmas demonstraram a compressão da atividade proposta. Mesmo que as respostas ou as propostas apresentadas não estejam totalmente corretas, observa-se que as equipes elaboraram uma estratégia de resolução, elencaram hipóteses, entre outros, passos esses importantes para o desenvolvimento de raciocínio lógico.

Para o desafio de 2014, as equipes tinham à disposição fones de ouvidos para ouvir a música durante o desenvolvimento da programação. O desafio requer o emprego de conceitos matemáticos, tais como: variáveis e listas necessários para armazenar sequências de notas; intervalos musicais, isto é, distância entre duas notas; e codificação e decodificação das notas. Além disso, os competidores tinham que conhecer princípios básicos de música, como ritmo, compasso, batidas, entre outros. Estes conhecimentos foram construídos através dos desafios semanais preparatórios para a competição.

Para análise da programação do desafio, foram escolhidas as equipes Machado da da Escola Estadual de Ensino Fundamental Dr João Carlos Machado, do município de Sarandi e SSPR da Escola Municipal de Ensino Fundamental Giocondo Canali, do município de Tapejara, respectivamente, primeiro e terceiro lugares desta 2014.

A equipe Machado cumpriu com os requisitos solicitados para a resolução do desafio. A equipe conseguiu controlar a execução da sequência musical, utilizando-se da lista criada. Ela também programou a interação entre Sprite e palco seguindo o ritmo da música. A figura 5 apresenta detalhes da solução proposta pela equipe. 

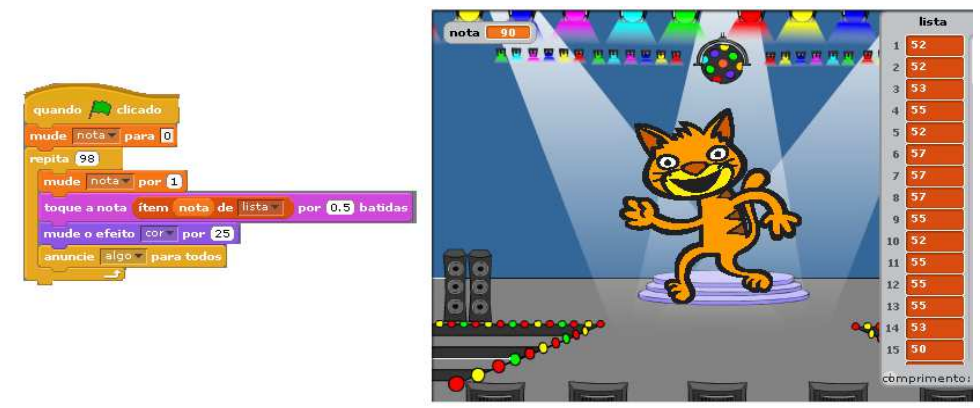

Figura 5. Programação da sequência musical e execução da programação no palco

A equipe SSPR cumpriu parcialmente os requisitos do desafio. Criou a lista solicitada, porém não a utilizou na programação da sequência musical. Construiu a sequência através da repetição de blocos, conforme indicado na figura 6 .
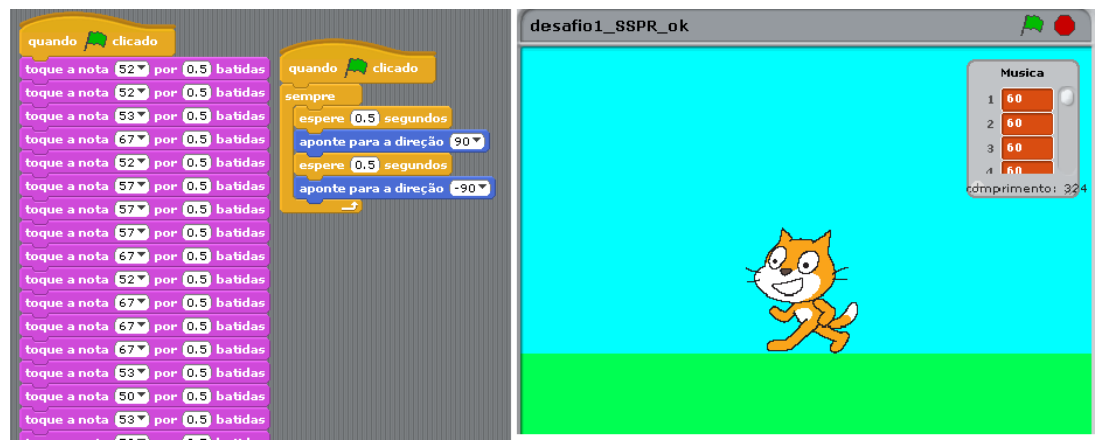

Figura 6. Bloco de comandos e palco de execução da programação.

O não cumprimento de alguns requisitos pela equipe SSPR pode indicar dificuldades na interpretação do desafio ou de lógica de programação, uma vez que não conseguiram utilizar a lista para programar a sequência musical.

Segundo Smole e Diniz, "o aluno, falando, escrevendo ou desenhando, mostra ou fornece indícios de que habilidades ou atitudes ele está desenvolvendo e que conceito ou fatos ele domina, apresenta dificuldades ou incompreensões." (2001)

Tendo em vista esta afirmação, é que se pode comprovar que os competidores de algumas equipes tiveram dificuldades na interpretação do enunciado do desafio e, posteriormente, na elaboração da estratégia de resolução, fazendo com que não fossem cumpridos todos os requisitos solicitados.

\section{Considerações Finais}

Com a realização das duas edições da olimpíada, é perceptível nas escolas participantes o desacomodar de alunos e professores frente ao uso de novas tecnologias nas práticas escolares. Isto é comprovado através do relato de uma das professoras participantes:

Estou agradecendo ao pessoal que se disponibilizou a vir na Escola.Estadual de Ensino Médio Ernesto Tocchetto, para orientar e instalar o programa do Scratch para os membros da equipe e se inteirarem das tarefas para as olimpíadas de programação. Professora orientadora, a senhora está de parabéns por esse dia. Esta semente foi plantada. Estou muito feliz por encontrar pessoas como esse grupo que nos presenteou 
com o auxilio e a dedicação de acreditar que podemos juntos utilizar a informática e a tecnologia para a formação de nossos adolescentes.

É importante ressaltar que, a partir da participação da escola citada na olimpíada de 2014, vários alunos passaram a participar de oficinas de programação utilizando o Scratch, com a orientação da professora e da equipe competidora.

Assim, de acordo com Valente e Almeida(1999), as tecnologias da informação e comunicação podem proporcionar novas formas de aprendizagem, modificando as relações entre professores e alunos, ou entre alunos e alunos e entre alunos e conhecimento.

Usando o Scratch, os estudantes deixam de ser somente usuários de computador, passam a ser seus programadores, dessa forma tornam-se cidadãos mais livres para criar e expressar suas ideias e convicções.

\section{Referências}

Gewerc, Adriana y Almudena Alonso-Ferreiro (2014) "Enriquecimiento de la enseñanza con tecnologías. La visión del alumnado". RELATEC Revista Latinoamericana de Tecnología Educativa Web: http://campusvirtual.unex.es/revistas Vol 13(1), 75-87

Lévy, Pierre (1999) “Cibercultura”, Tradução de Carlos Irineu da Costa, São Paulo:Ed.34.

Marques, M. T. P. M. (2009) "Recuperar o engenho a partir da necessidade, um recurso às tecnologias educativas: contributo do ambiente gráfico de programação o Scratch em contexto formal de aprendizagem". (Tese de Mestrado em Ciências da Educação, Universidade de Lisboa). Recuperado 10, junho 2012 em http://repositorio.ul.pt/handle/10451/847.

Papert, S. (1986) “Logo: computadores e educação”. Brasiliense, São Paulo, Brasil.

Pinto, A. S. (2010). "Scratch na aprendizagem da Matemática no $1 .^{\circ}$ Ciclo do Ensino Básico: estudo de caso na resolução de problemas". Dissertação (Mestrado em Estudos da Criança). Universidade do Minho, Minho, Portugal.

Pozzo, J. I. (2002). “Aprendizes e Mestres: a nova cultura da aprendizagem”. Porto Alegre: Artmed.

Smole, K. S.; Diniz, M. I. (2001) "Ler, escrever e resolver problemas: habilidades básicas para aprender Matemática”, Porto Alegre: Artmed.

Valente, J. A., Almeida, F. J. (1999) "Visão analítica da informática na educação no Brasil: a questão da formação do professor", http://www.professores.uff.br/hjbortol/car/library/valente.html, junho 2014. 